\title{
Exploring a food system index for understanding food system transformation processes
}

\author{
Siemen van Berkum ${ }^{1}$ (D) $\cdot$ Ruerd Ruben ${ }^{1}$ \\ Received: 16 March 2021 / Accepted: 27 June 2021 / Published online: 3 August 2021 \\ (C) The Author(s) 2021
}

\begin{abstract}
Whereas most indicators for food systems performance only focus on outcomes, we explore the prospects for a kind of Food Systems Index (FSI) that tries to capture several key components that influence differences in food system performance at country level. We outline the theoretical foundations and methodological approach underlying the FSI framework and illustrate its relevance for understanding major food system characteristics. We therefore focus on major FSI differences between regions and types of countries and compare FSI outcomes across different types of food systems and in relationship to other indicators of change in the rural and economic structure. We explain the potential of the FSI framework for identifying more coherent food system policies but also acknowledge the challenges for its further operationalization.
\end{abstract}

Keywords Food system $\cdot$ Index approach $\cdot$ Country comparison $\cdot$ Typology $\cdot$ Policy coherence

\section{Introduction}

Within the framework of the preparations for the upcoming United Nations (UN) Food Systems Summit in 2021, there is growing interest in approaches that enable to assess driving forces of food systems transformation pathways and their implications for the Sustainable Development Goals (SDGs). To support the discussion on different programs and investments required for food system transformation, we engaged in the development of a food system index (FSI) to characterize how countries perform on different key indicators concerning food system drivers, components and outcomes.

Food systems include all elements and activities related to the production, processing, distribution, preparation and consumption of food, the market and institutional networks for their governance, and the socio-economic and environmental

This article belongs to the Topical Collection: Food System Transformations for Healthier Diets, Inclusive Livelihoods and Sustainable Environment

Guest Editors: Romina E Cavatassi, Leslie Lipper, Ruerd Ruben, Eric Smaling, Paul Winters

Siemen van Berkum siemen.vanberkum@wur.nl

1 Wageningen Economic Research, Wageningen University \& Research (WUR), Pr. Beatrixlaan 582 - 528, 2595, BM Den Haag, The Netherlands outcomes of these activities (HLPE, 2017). Food systems analysis is based on systematic appraisal of different underlying processes that influence food availability, access and utilization, as well as a detailed analysis of the roles of different stakeholders involved. It requires a thorough understanding of the structure of a food system and the dynamics of food system changes over time and space in relation to predefined societal, environmental or distributional goals (Ruben et al., 2019).

An effective food system provides food security and nutrition for all people in a sustainable manner and is essential to promote and maintain the well-being of people and the resilience capacity of the planet. Food security, as defined by the Food and Agriculture Organization (FAO) (CFS, 2014), traditionally has four pillars: availability, access, utilization and stability. These pillars contribute to three types of outcomes in terms of nutrition, sustainability and livelihoods that provide the foundations of a desirable food system. Food systems are key to achieve several SDGs.

Whereas several efforts have been made in the past to develop particular indices for measuring food security, hunger and nutrition, until now limited attention has been devoted to the design of an index that captures more comprehensive aspects of food systems and covers in a coherent manner the linkages between multiple components of food production, food distribution and food consumption (Béné et al., 2019). Moreover, differences in food system performance are related to other transformative processes in the economic structure 
and in the rural society. It will also help to better understand how public policies and private sector investment can influence the performance of the food system.

The main aim of this article is to identify the prospects for an integrative approach to capture main features of food system performance at country and regional level, and to identify how food system transformations are related to other structural changes in the economy and in the agricultural sector. This may contribute insights into the driving forces and constituencies that influence the structure and dynamics of food system. It also reveals the complexities of food system analysis and highlights priorities for further analysing food system transformation processes.

As the result of very useful international initiatives for systematic data collection on key components of food systemsmainly led by the Rome-based UN agencies, the World Bank and several private sector agencies (Barilla Centre, WBCSD, WEF) and civic organizations (Oxfam UK, Welthungerhilfe Germany), there is increasing attention for understanding the driving forces of food systems change and therefore required accurate and consistent food and nutrition data. Data with periodical updates not always common and time series data still remains rare. The recently launched Food Systems Dashboard (FSD, downloadable at https:// foodsystemsdashboard.org/) makes laudable efforts to bring together data from different sources and several food system components (Fanzo et al., 2020).

Based on these previous efforts and ongoing initiatives, it is considered increasingly important to be able to track and trace differences in food system performance between countries and regions, and to understand how structural factors and policy priorities may influence food systems outcomes. The FSI intends to relate food systems drivers and components to food system outcomes at country level where major decisions on food policies and investments are taken. We need a thorough understanding of the linkages, feedbacks and interconnection between food system components to be able to trace the effects of more coherent public and private action.

The analytical basis for the FSI is grounded in the seminal High Level Panel of Experts (HLPE) food systems report (, 2017) that introduces a clear distinction between (exogenous) food systems drivers and (endogenous) food system outcomes. It identifies three core food systems components: food production and food markets, the institutional food environment and food consumption and nutrition. This traces back to key aspects of food availability (supply of sufficient food), food access (through different distribution channels) and food utilization (adequacy of consumptive intake and dietary diversity). Other aspects related to stability (resilience of food systems against climate or market shocks) and affordability (relative prices of food compared to incomes, as well as food price volatility) are becoming increasingly important and should be included in subsequent versions.
The food system index intends to enable the assessment of food system structure, behaviour and performance of individual countries, and of groups of countries located in particular regions (Africa, Asia, Latin America) and according to their development stage (low, middle and high income countries). Moreover, the FSI outcomes can be compared to other indicators of system change in areas such as socio-economic integration as well as adjustments in the agrarian and rural structure. Other comparative analysis that can be made in perspective through the FSI framework refer to differences with respect to the coherence of food systems policies, the impact of public and private investments, and the comparison of diversity of food systems between (and within) countries.

A food system index that simultaneously captures different indicators can be useful to compare countries/regions and monitor and track their progress toward improved food system. It may thus support policy makers to adequately focus policy interventions and it could offer guidance to private agents to identify investment opportunities for improving food systems. Moreover, it can become a tool to assess structural deficiencies in food systems that ask for deliberate (inter) national action.

Our analysis is structured in five consecutive steps. First, we outline the underlying principles for the FSI approach and we discuss its methodological foundations (section 2). Second, we define six key FSI dimensions that characterize food systems performance and identify main indicators for their measurement (section 3). Third, we look at differences in FSI performance between categories of countries and geographical regions to assess its usefulness (section 4). Fourth, we aggregate the different FSI dimensions into a single index to enable a comparison between different types of food systems (section 5). Fifth, we show how FSI performance relates to wider aspects of economic and agrarian change and identify their linkages to food system transformation (section 6). We conclude with a discussion on the prospects for using the FSI framework to better understand policy coherence for food systems transformation and outline the challenges for its further operationalization (section 7).

\section{Criteria for an integrative food systems approach}

For the initial development of the Food Systems Index, we started with an inventory of publicly available data sets that are related to the key dimensions of the HLPE (2017) food systems framework and can be derived from international initiatives on SDG progress tracking. Hereafter, we looked at already existing indices developed by different agencies in recent years, to assess their relevance for aspects of food systems performance and change. Based on this information we were able to develop a set of key requirements that the food 
system index should meet in order to be able to address the before-outlined analytical and policy challenges.

For the selection of indicators, it $\mathrm{t}$ is important to consider the general methodological guidelines for SMART criteria. Indicators should be Specific (also avoiding multicollinearity between indicators), Measurable (registering major achievements), Available and achievable (within reach of key stakeholders), Relevant for policy-making, and Time bounded (realistic time frame for change). Moreover, practical considerations related to data available and efficiency need to be considered.

Regarding the availability of cross-country data sets on food and nutrition, substantial progress has been reached in terms of standardization and coverage (Allee et al., 2021). Global information on dietary intake and nutrition (and related health outcomes) has become widely available from UN, FAO, World Health Organisation (WHO) and Global Nutrition Report (GNR). Less data is gathered concerning critical components of diets: diet diversity, stability and affordability. Country-level data on food production and trade (food balance sheets) is well accessible, but accurate data on (relative and absolute) food prices and food outlet choices by consumers is still scarce. Information on crop yields, input use (fertilizer and irrigation), average farm size and agricultural employment is still based on rather rough estimations.
Recent data on global food system drivers (such as urbanization, population growth, climate change, trade and poverty) is readily available from international agencies (International Panel for Climate Change [IPCC], World Bank, World Population Council, etc.).

Several concerted efforts have been made for bringing together several indicators on critical aspects of the food system (see Table 1 for an overview). Notwithstanding their relevance for particular purposes, most indices have a specific focus (either nutrition, poverty or climate) and are limited in their geographical coverage (and usually only focus on developing countries). Moreover, these indices are produced for a particular audience (nutritionists, food business, donor agencies) and therefore rarely capture interactions between different components of the food system. Finally, several indices are not regularly updated and therefore have limited time sensitivity. The recently published Food Systems Dashboard is in this respect a notable positive exception.

As can be noted, most of these indicator frameworks take hunger and malnutrition as starting point, sometimes also including attention for the dimensions of sustainability and inclusion. Some indices are particularly focused on food loss and waste, micronutrient deficiency, or changes in diets or consumption patterns over time. Most indices focus on changes in a single indicator and devote little attention to

Table 1 Overview of indices for Food Security and Nutrition

\begin{tabular}{|c|c|c|c|}
\hline Initiative & Goal & Agency & $\begin{array}{l}\text { Coverage } \\
\text { (\# of countries) }\end{array}$ \\
\hline $\begin{array}{l}\text { Global Nutrition Report } \\
\text { (GNR) }\end{array}$ & $\begin{array}{l}\text { Status of malnutrition around the world } \\
\text { (stunting, wasting, overweight) }\end{array}$ & $\begin{array}{l}\text { Development Initiatives / } \\
\text { 2013-2018 }\end{array}$ & 141 countries. \\
\hline $\begin{array}{l}\text { Global Hunger Index } \\
\text { (GHI) }\end{array}$ & $\begin{array}{l}\text { Comprehensive measure and track hunger at the global, regional, } \\
\text { and country levels }\end{array}$ & $\begin{array}{l}\text { Concern Worldwide and } \\
\text { Welthungerhilfe / } \\
\text { 2006-2018 }\end{array}$ & 119 countries, \\
\hline $\begin{array}{l}\text { Global Food Security } \\
\text { Index (GFSI) }\end{array}$ & $\begin{array}{l}\text { Drivers of food security - considering affordability, availability, } \\
\text { quality and resilience - across both developing and developed } \\
\text { countries }\end{array}$ & $\begin{array}{l}\text { The Economist Intelligence } \\
\text { Unit (EIU) / 2012-2018 }\end{array}$ & $\begin{array}{l}113 \text { countries, } 28 \\
\text { indicators }\end{array}$ \\
\hline $\begin{array}{l}\text { Access to Nutrition } \\
\text { Index (ATNI) }\end{array}$ & $\begin{array}{l}\text { Rating food and beverage manufacturers' nutrition-related policies, } \\
\text { practices and disclosures worldwide on a recurrent basis }\end{array}$ & $\begin{array}{l}\text { ATN Foundation / } \\
\text { 2013-2016-2018 }\end{array}$ & $\begin{array}{l}22 \mathrm{~F} \& \mathrm{~B} \text { manufacturers } \\
\text { operating in } 200 \\
\text { countries }\end{array}$ \\
\hline $\begin{array}{l}\text { Food Sustainability } \\
\text { Index (FSI) }\end{array}$ & $\begin{array}{l}\text { Food system sustainability across three categories: Food Loss and } \\
\text { Waste, Sustainable Agriculture and Nutritional Challenges }\end{array}$ & $\begin{array}{l}\text { Barilla Centre for food \& } \\
\text { nutrition (BCNF) with EIU } \\
\text { / } 2018\end{array}$ & $\begin{array}{l}67 \text { countries; } 38 \\
\text { indicators \& } 90 \\
\text { metrics }\end{array}$ \\
\hline $\begin{array}{l}\text { Global Food Index } \\
\text { (GFI) }\end{array}$ & $\begin{array}{l}\text { Best and worst places in the world to eat, and challenges for getting } \\
\text { enough of the right food (enough to eat / affordability / obesity) }\end{array}$ & Oxfam / 2018 & 125 countries \\
\hline $\begin{array}{l}\text { Health \& Nutrition } \\
\text { Commitment Index } \\
\text { (HANCI) }\end{array}$ & $\begin{array}{l}\text { Ranking governments on their political commitment to tackling } \\
\text { hunger and undernutrition }\end{array}$ & $\begin{array}{l}\text { Institute of Development } \\
\text { Studies (IDS), Sussex / } \\
2013\end{array}$ & $\begin{array}{l}45 \text { countries; } 14 \\
\text { indicators }\end{array}$ \\
\hline World Obesity & $\begin{array}{l}\text { Drivers of Obesity, the Impact of Obesity and Actions to prevent } \\
\text { and manage Obesity }\end{array}$ & $\begin{array}{l}\text { Global Obesity Observatory / } \\
2018\end{array}$ & EU Member countries \\
\hline What the World Eats & $\begin{array}{l}\text { Changes in consumption patterns over } 50 \text { years (in grams \& } \\
\text { calories per person) }\end{array}$ & $\begin{array}{l}\text { National geographic (based } \\
\text { on FAOStat) / 1961-2011 }\end{array}$ & 22 countries \& world \\
\hline Our World in Data & $\begin{array}{l}\text { Diet composition \& food prices; undernourishment \& } \\
\text { Micronutrients }\end{array}$ & $\begin{array}{l}\text { Oxford Open Data Lab - Max } \\
\text { Roser / 2000-2017 }\end{array}$ & 157 countries \& regions \\
\hline
\end{tabular}

Source: own compilation 
relationships between different indices. Few indexes have a global coverage, and attention for food governance and private sector food and business practices remains fairly limited.

Based on these experiences, the design and operationalization of a new Food System Index (FSI) that can be used for country comparison and for the identification of leverage points towards food system transformation, should respond to the following set of criteria:

- The FSI should include all countries (UN member states, both developing and developed countries) that provide regular information, in order to enable cross-country comparison;

- The FSI needs to be based on publicly accessible data that is validated by respected international agencies;

- The FSI needs to use simple indicators that represent key dimensions of the food system and are collected on a regular base;

- The FSI indicators should be sufficiently sensitive to change over time;

- The FSI indicator framework should be able to capture key aspects of the food system, ranging from drivers (inputs) to components (throughput) to outcomes (output \& impact);

- The FSI can be used for description and analysis of the food system structure, conduct and performance;

- The components of the FSI index permit an understanding on the linkages between drivers and outcomes of food system transformation;

In order to be able to respond to these multiple challenges, the FSI cannot be considered as a mere tool, but responds to a theory-based understanding of food systems change. Based on knowledge and understanding of (partial) relationships between the different aspects and components of the food system, some main indicators can be selected that represent relevant proxies for the key food system dimensions (and can also be modified if theory asks for it).

\section{Framework for FSI development}

For developing a food system index that responds to the before-mentioned criteria, it is necessary to use transparent procedures that guide its construction, calculation and maintenance. Since the FSI is intended to be used to assess country-wide food systems status and to trace progress in food systems transformation, we need a relatively simple but sensitive set of indicators, preferably without applying any deliberate ex-ante weighing. Important FSI properties refer to its relevance in different contexts and its potential use for priority setting and decision-making on (public and private) investments that contribute to better-performing food systems.

The FSI design is based on three interrelated aspects: (a) structural factors that drive food systems, (b) food systems components that reflect activities of food system stakeholders, and (c) multiple food system outcomes including the likely trade-offs between them. These three aspects are derived from the structure conduct - performance (SCP) framework originally developed by Bain (1959) as an analytical tool to assess the influence of external (market and institutional) drivers for decision-making on product and process innovations. Structure drives comprise exogenous trends in population growth, economic growth, climate and technology change that simultaneously influence the performance of all food system components (e.g. production, distribution, consumption and governance). Performance attributes capture outcomes of food system behavior in terms of nutrition, environment, inclusion and equity (see Fig. 1).

We apply this SCP framework to the food systems transformation process by focusing on changes in food systems components and outcomes. Therefore we need to identify relevant indicators that capture most important adjustments. Since structural drivers are considered as exogenous factors (only subject to long-term change) these indicators are less suitable to characterize the policy space for food systems transformations. Instead, we include the dimensions of domestic food production, trade, consumption and policies to reflect the solution space as determined by different structural demographic, technological, macroeconomic and environmental drivers.

Most attention is given to the components that characterize food system dynamics in terms of access, availability, affordability and attractiveness for (public \& private) investments. The interactions between these components of food production, food markets and trade, food consumption and the food governance structure influence the activities by different stakeholders and their capacity to respond to shocks, thereby shaping opportunities for food system adjustment.

The outcome dimensions focus on the triple burden of malnutrition but also include implications for climate and the environment. Given the scarcity of data on income and wealth distribution, we opted to address inclusiveness outcomes as part of the food consumption component. If more appropriate data become available, new FSI versions should consider (changes in) land distribution (Gini ratio) or smallholder production shares as part of the food system outcomes.

Table 2 shows the key dimensions that represent food system components and outcomes, and the selected indicators that illustrate the performance on each of these dimension. All indicators are taken from publicly available sources and 
Fig. 1 SCP framework for food systems analysis

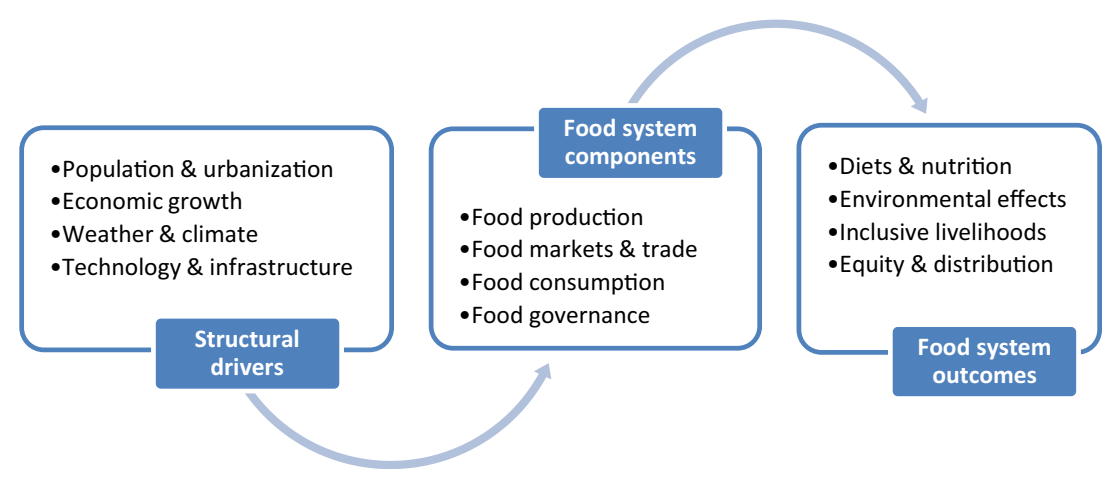

scaled between 0 and 100 to bring them on identical terms. ${ }^{1}$ We rely on unweighted aggregation, which means that each indicator has the same weight within a certain dimension, and that all dimensions are equally valued. The presentation of these outcomes in spiderwebs for individual countries and different categories of countries allows for comparison.

We refrain from a separate specification of the structural drivers, since these are largely reflected in the behaviour of the different food system components. Changes in demographic structure and economic growth tend to increase commercial food demand and reinforce food markets, and urbanization translates into a larger number of net food buyers (Vandercasteelen et al., 2018). On the other hand, while progress in technologies and investments in infrastructure will support food production and processing for greater domestic availability, weather variability and climate change have adverse effects of food production and also enhance volatility in food markets. (Christiaensen \& Todo, 2014).

The reliance on indicators and dimensions with equal weights has implications for the analytical structure of our analysis. Since there are no ex-ante criteria to justify any weighing, we give equal importance to food supply, food production and the food environment components. This does not mean, however, that certain type of interventions could be more or less effective for reaching particular food system outcomes. Moreover, we acknowledge that budgetary implications of particular measures are widely different and such costs also influence policy choice. We are well aware of these limitations, but believe that results will only slightly vary, since our analysis does not focus on food system changes at

\footnotetext{
1 The rating from 0 to 100 for each indicator is determined by the following formula: ((country's individual score on the indicator minus the lowest score on the indicator)/(highest score minus lowest score on the indicator) $)^{*} 100$. With this formula the country with the highest score rates 100 and the one with the lowest rates zero, with all other countries in between, relative to their distance from both the lowest and highest scores. Some dimensions are made up of two, others of three or more indicators. The overall rate on a dimension is the unweighted average of indicators. Given that some indicators indicate better performance as the value of the indicator decreases (e.g. import tariffs, stunting, wasting), the scales for these indicators are inverted, such that increasing scores indicate more desirable outcomes for all variables.
}

the level of individual countries but rather makes an aggregated analysis between categories of country.

The construction of the FSI is based on the identification of data sets that are publicly available and sufficiently representative for each of the dimensions. The selection of indicators is guided by conceptual and empirical research concerning interactions between relevant food system components (Brouwer et al., 2020; Ruben et al., 2019). In the following, we discuss the rationale for each of the six FSI dimensions and for the choice of related indicators.

At the component level, food production and domestic food availability are strongly influenced by the quality of natural resources (land, water) as well as the technical capacities for improving potential yields. The latter is usually a function of input use (seeds, fertilizers, facilitated by access to rural credit) and external infrastructures (irrigation/mechanization) that in turn shape rural labour absorption and agricultural land and labour productivity. Taken together, land use and yields can be considered as key underlying factors for rural incomes and domestic food supply (Zhou \& Staatz, 2016).

Food markets and food trade are critical to accessibility and affordability in physical and in economic terms. Prices of key food items depend on local production and trade. Nutrient-dense foods such as fruits, vegetables and some animal-based foods are generally too expensive for local buyers. Imports could improve availability, whereas import tariffs stimulate domestic production (Hirvonen et al., 2019). Moreover, higher coverage and better quality of road networks reduce transport and transaction costs as well as trade risks, Trade reinforces linkages between rural and urban areas, and enables better access to food for poorer households, but also enhances consumption of processed food (usually sold in supermarkets) that are associated to growing overweight and obesity.

Food consumption and affordable diets strongly depend on food prices and household income and are therefore related to both the level of income (i.e. higher food demand and lower food expenditure share with rising incomes) as well as the distribution of incomes (shown in the Gini index). People and households up or below the poverty line represent a critical category that is likely to face shortages in major nutrients and thus extremely vulnerable to stunting and wasting (Cicera \& Masset, 2010). 
Table 2 Food Systems Index: dimensions and indicators

\begin{tabular}{|c|c|c|}
\hline Dimension & Indicator & Source and data used \\
\hline \multicolumn{3}{|l|}{ Food system components } \\
\hline \multirow[t]{2}{*}{ Food production (availability) } & Arable land per capita & FAOSTAT 2019; 2017 data \\
\hline & $\begin{array}{l}\text { Average yields } \\
\text { (cereals, pulses, roots \& tubers, milk and poultry meat) }\end{array}$ & FAOSTAT, 2018 data \\
\hline \multirow[t]{3}{*}{ Food Markets \& Trade (accessibility) } & Consumer price index & IMF, 2018 data \\
\hline & $\begin{array}{l}\text { Import tariffs (simple average of agriculture and food } \\
\text { products) }\end{array}$ & WTO, 2018 data \\
\hline & Road network (road density) & World Bank GRIP, various years \\
\hline \multirow{3}{*}{$\begin{array}{l}\text { Food Consumption } \\
\text { (Inclusiveness \& affordability) }\end{array}$} & Income per capita & World Bank WDI, average 2015-2018 \\
\hline & Gini-index of income inequality & World Bank WDI, various years \\
\hline & $\begin{array}{l}\text { Poverty rate } \\
\text { (\% of population below poverty line of USD } 1.90)\end{array}$ & World Bank WDI, various years \\
\hline $\begin{array}{l}\text { Food Governance } \\
\text { (Public Policies \& Private Investment) } \\
\text { sec }\end{array}$ & Ease of doing business index & World Bank, average 2019-2020 \\
\hline \multicolumn{3}{|l|}{ Food system outcomes } \\
\hline \multirow[t]{3}{*}{ Nutrition \& Health outcomes } & Child stunting/wasting & World Bank/UNICEF/WHO, 2016 data \\
\hline & Overweight children/adults & World Bank/UNICEF/WHO,, 2016 data \\
\hline & $\begin{array}{l}\text { Micronutrient deficiencies } \\
\text { (\% Anaemia among women of reproductive age) }\end{array}$ & World Bank/UNICEF/WHO, 2016 data \\
\hline $\begin{array}{l}\text { Climate \& Environmental resilience } \\
\text { outcomes }\end{array}$ & Climate adaption performance & $\begin{array}{l}\text { University of Notre Dame ND-GAIN, } 2017 \\
\text { data }\end{array}$ \\
\hline
\end{tabular}

Adequate indicators for public policies and private investments are usually difficult to find (Hospes \& Brons, 2016). The World Bank ease-of-doing-business index provides a commonly accepted indicator that captures differences in rules and regulations for starting and operating mainly SME-type of enterprises. It also includes aspects like security of property,
Fig. 2 FSI performance by degree of economic development (Country groups ranked to GDP per Capita)

\section{Food System Scores for Groups of Countries ranked to GDP per Capita}

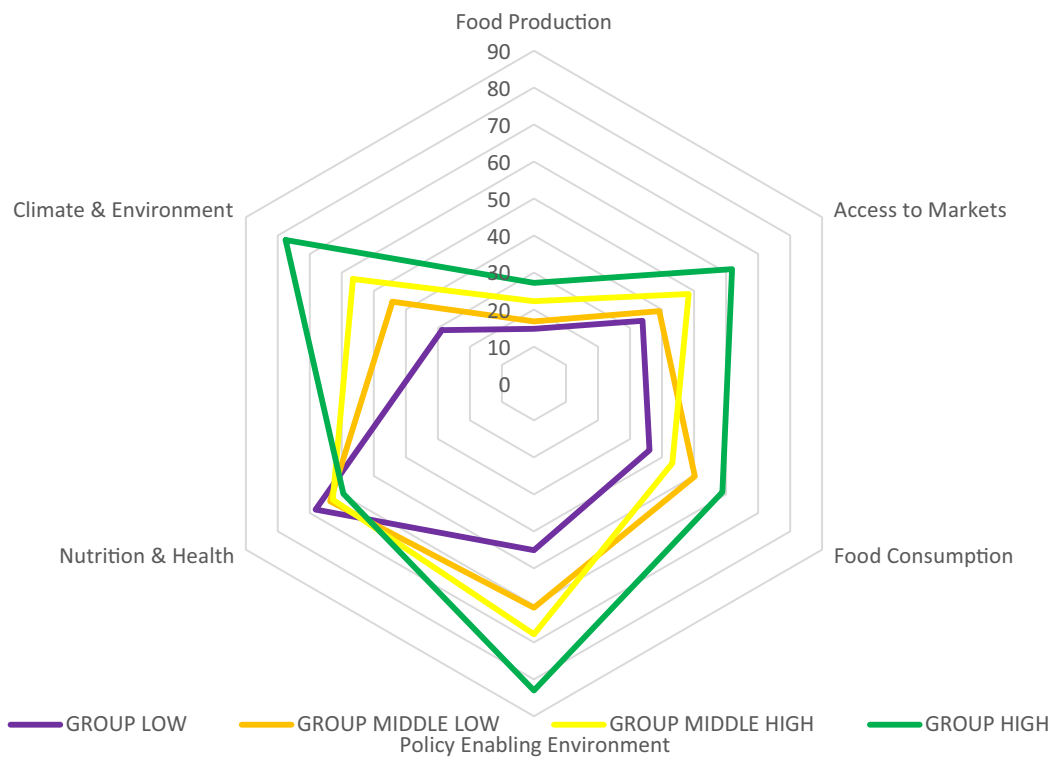


Fig. 3 FSI performance by macro regions

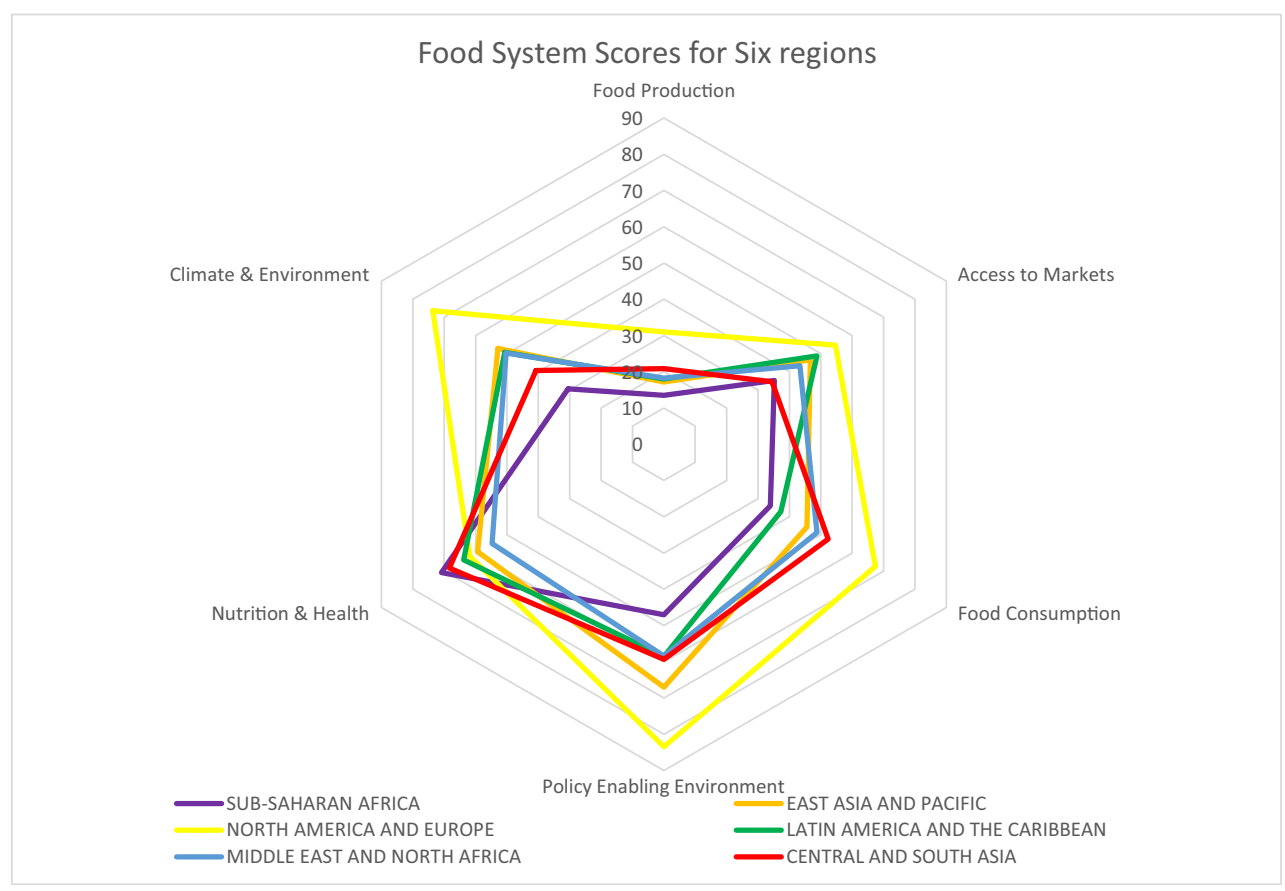

corruption (bribery) and legal frameworks for contract enforcement that are critical for enterprises in the food value chain.

At outcome level, there is broad agreement on the indicators used to measure stunting and wasting, overweight and obesity, and micronutrient deficiencies. Progress on these indicators is annually reported by organizations like WHO, FAO, Scaling Up Nutrition (SUN) and Global Alliance for Improved Nutrition (GAIN). It should be noted, however, that these outcomes are not exclusively caused by food system failures, but are sometimes also influenced by political turmoil or local conflicts. Moreover, there are important differences in nutrition between and within categories of household that are explained by gender, location (urban/rural), age, wealth, education and household size (Kennedy \& Peters, 1992; Sassi, 2020).

Environmental and climate outcomes of food systems should pay attention to short-term variability and long-term resilience. There is an abundance of environmental indicators developed by IPCC, World Resource Institute (WRI) and others that mostly look at climate adaptation. The University of Notre Dame developed a global adaptation index for 177 countries that captures both vulnerability and response capacity. It should be noted that this index mainly reflects the impact of climate on food supply, but far less the influence of diets on climate (Chen et al., 2015).

For the cross-country analysis we use the individual components that do justice to the multi-dimensional nature of food systems (Allee et al., 2021) and mirror the conceptualization of multidimensional poverty. However, for the ranking of countries and the comparison of food system transformation with other structural change processes, it is attractive to have an aggregated index at our disposal. Therefore, we group countries in low, medium and high FSI performance based on the interactions between food production, food trade, food consumption and food governance (HLPE, 2017: Glopan, 2016).

In the future, we would like to be able to include indicators for two frequently overlooked cross-cutting dimensions, namely the formal and informal markets (Delaney et al., 2018) and the gender-disaggregated access to food (Malapit et al., 2020). While the former refers to the relationships between large and smaller stakeholders and their incidence on food governance arrangements, the latter looks at bargaining differences between agents and particularly considers inequality by gender, age, ethnicity or other individual or group characteristics and their impact on nutrition and diets (D'Odorico et al., 2019; Harris et al., 2020).

Otherwise, we would like to identify some composite indicators that capture simultaneous changes in food production, distribution and consumption. Variables such as the food share in household expenditures (that tends to decrease with higher levels of economic development) or the market purchase of food products (related to higher urbanization and more specialization) may be options to consider.

\section{Comparative appraisal of country FSI performance}

As a first test to assess the validity of the index, we apply the FSI by comparing the values of its six dimensions (see 
Table 2) for (groups of) countries at different stages of economic development. The country scores were determined for all six dimensions, and scores of countries belonging to the same income group were added together and divided by the number of countries belonging to the group, to determine an average performance. Figure 2 shows major differences between low- and high-income countries, where low-income countries score less well on almost all dimensions of the food system.

Low income countries generally have a strong food demand and at the same time limited production capacities, which most likely indicates higher food import dependence. Also, access to food markets scores low. These scores indicate a fragile food security situation in general for this group of low-income countries. The low-income group's vulnerability to sudden food price increases is illustrated by the low score on food consumption inclusiveness, as a substantial share of population lives below the poverty line. Low scores on the food security indicators are accompanied by a poor ranking on the policy enabling environment dimension, emphasising weak institutional capacities to enhance business activities and protect property rights (a key condition for making productive investments).

There is remarkably little difference with the high income countries when it comes to score on the nutrition and health dimension. This can be explained by the fact that while low income countries face high scores on child stunting/wasting and micronutrient deficiencies, many of the high income countries increasingly suffer from child and adult overweight. These two opposing trend may substitute for each other during the process of economic development.

Figure 3 shows the FSI results for six different geographical regions. Scores for Sub-Saharan Africa reflect those of the low-income countries group above, while North-America and Europe are in line with the high-income economies. Food systems in East Asia score higher on public policy involvement and inclusiveness, whereas Latin America is strongly developed in terms of infrastructure and accessibility but also suffers from being more susceptible to climate change (related to large-scale deforestation), as do all regions except North America and Europe.

\section{Using the FSI for distinguishing different food systems archetypes}

We can now use the FSI for linking country-level FSI scores with different types of food systems in order to enable a comparative analysis of food systems. For this purpose an average FSI was calculated for each country by determining the (unweighted) average score of all six dimensions of the index. Subsequently, an unweighted average index for the country category was determined.
The HLPE (2017) report makes a differentiation between three types of food systems: traditional, mixed (transitional) and modern. This classification is based on two dimensions: (a) the food environment and (b) food supply chains. Specific criteria are related to diet composition (staples, simple or advanced food processing), marketable surplus (from food self-sufficiency to net sellers and finally to net buyers), reliance on trade channels (local trade, urban markets, international trade) and type of market outlets (local exchange, wet markets, modern retail). Consequently, traditional systems tend to give priority to food availability and access, whereas in mixed systems issues like affordability and food safety become more important. Modern food system are characterized by relatively lengthy supply chains with more (partly imported) processed and packaged food distributed through supermarkets and out-of-home consumption. ${ }^{2}$

For our purposes we build on the new food system classification by Fanzo et al. (2020) that has been presented in the recently launched Food System Dashboard https://foodsystemsdashboard.org/) where countries are differentiated according to the diversity in diets and the development of (local) food markets. This results in five food systems archetypes that capture important differences in terms of agriculture value added per worker, share of dietary energy from cereals, roots, and tubers, number of supermarkets per 100,000 population and percent urban population of total population. The food system dashboard (FSD) distinguishes five different archetypes:

- Rural and traditional. Farming mainly done by smallholders, with low agricultural yields and limited diversity. Scarce infrastructure results in seasonal variation and large food losses. Most food is sold locally in informal open market, small shops and street vendors.

- Informal and expanding. Rising incomes, formal employment and urbanization, with demand for processed and packaged foods from locally-sourced and imported ingredients. Coexistence of informal markets (fresh food) and supermarkets (convenience foods) but limited quality standards and no regulation.

- Emerging and diversifying. Increasing number of medium- and large-scale commercial farms linked to markets. Modern supply chains for fresh foods, and

\footnotetext{
2 Another interesting typology of food environments is further elaborated by Downs et al. (2020) making difference between a wild, cultivated, and built food environment. Food availability, affordability, convenience, promotion and quality (or desirability), and sustainability properties of food products for each food environment type are identified. Their paper presents a methodological approach with potential methods for assessing different properties of the food environment, but is mainly conceptual, not offering measurements or empirical data.
} 
supermarkets expansion to smaller towns. Processed foods are common in urban and many rural areas, but fresh food continues to be acquired through informal markets.

- Modernizing and formalizing. Higher agricultural productivity and larger farms that rely on mechanization and input-intensive practices. More sophisticated food infrastructures result in fewer food losses. Food imports enable year-round availability of diverse basket of foods. Public safety and quality regulation is common.

- Industrialized and consolidated. Large-scale, input-intensive farms serve specialized markets. Supermarket density is high and formal food sector captures nearly all of the food intake, including fresh foods, fast food and home delivery. Food policies focus on banning trans fats and the reformulation of processed foods.

We use the classification defined by the dashboard that divides countries into these five categories, to assess whether the FSI index ranking is in line with the FS Dashboard classification of countries. Given the characteristics of the classification we expect to find a higher aggregate food system index when we move from the spectrum starting with the Rural and Transitional group towards the more Industrialized and consolidated group. Table 3 indeed confirm that FSI scores are consistently lower for Rural and Transitional countries and gradually increasing for countries that are characterized by more Formalized, Industrialized and Consolidated archetypes.

Table 3 provides descriptive statistics of key variables in our data set. It shows the average FSI, its standard deviation, and the minimum and maximum value for each country group and for all countries included in these typologies. The average FSI is 50, with a standard deviation of 11 . Note that the standard deviations of the five country categories are relatively small, which means that there are few differences between the scores of individual countries and that the groups are quite homogeneous.

\section{Food system transformation: Linking economic, agrarian and food system change}

The FSI framework also provides interesting opportunities to assess the food system transformation potential at various levels of agrarian change and economic development. Suitable indicators for the latter are derived from the agricultural transformation framework developed by Timmer (1988). It makes a distinction between two major structural changes:

- progress in rural transformation (RT) that can be assessed by looking at the rising agricultural value added per worker,

- progress in structural economic transformation (ST) that is reflected by the growing share of non-agricultural activities in GDP.

Table 3 already illustrates that changes in FSI largely coincide with higher RT and ST scores over different food system architypes. Fig. 4 shows how food systems archetypes are related to indicators of structural transformation (value added non-agricultural activities as \% GDP) and progress in rural transformation (value added per agricultural worker). The rural \& traditional (RT) food system archetype prevails in countries with low levels of ST and RT. The Informal \& Expanding (IE) archetype is slightly more advanced in the ST field but remains with stagnating levels of agricultural productivity. Major changes occur in the transition from Emerging \& Diversifying to Modernizing \& Formalizing food systems that show considerable increase in non-agricultural activities, but only slightly higher agricultural productivity. Finally, industrialized \& consolidated food systems maintain both a high share of industrial (non-agricultural) production in GDP as well as a high agricultural productivity that permits feeding the growing urban population.

Different food system archetypes tend to emerge under certain conditions of Structural transformation (ST) and agricultural transformation (RT). Looking at the relationships between the three transformation processes could offer important insights in food systems archetypes under different

Table 3 Food system index scores for different types of food systems

\begin{tabular}{|c|c|c|c|c|c|}
\hline FS Dashboard country classification & Average FSI & Standard Deviation & Minimum FSI & Maximum FSI & $\mathrm{N}$ \\
\hline Rural \& transitional & 37.8 & 5.1 & 26.3 & 46.4 & 30 \\
\hline Informal \& Expanding & 43.5 & 7.0 & 29.0 & 58.7 & 29 \\
\hline Emerging \& Diversifying & 50.4 & 5.8 & 40.2 & 64.3 & 27 \\
\hline Modernizing \& Formalising & 55.2 & 6.7 & 41.6 & 65.4 & 31 \\
\hline Industrialised \& Consolidated & 64.0 & 5.9 & 45.0 & 73.6 & 29 \\
\hline All countries & 50.2 & 11.0 & 26.3 & 73.6 & 146 \\
\hline
\end{tabular}

Source: authors' calculations 
a

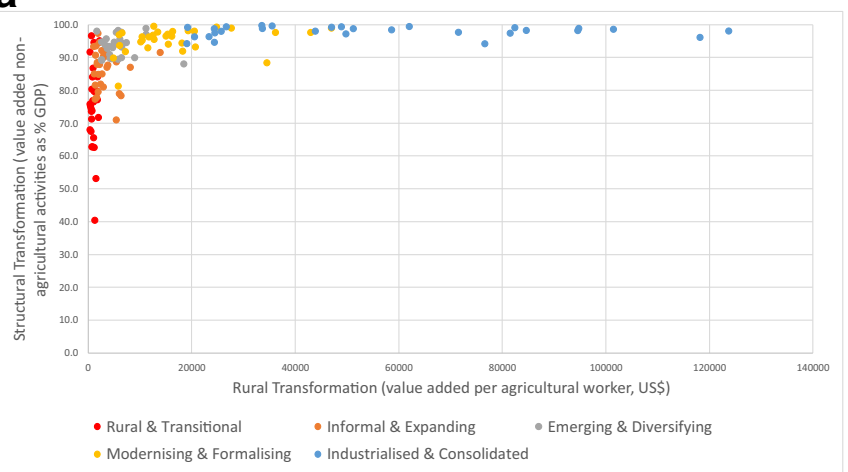

b

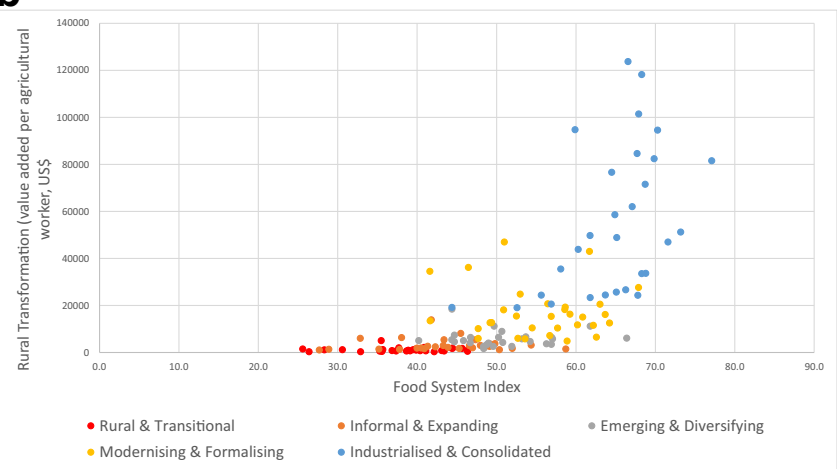

Fig. 4 a and b Food systems archetypes by degree of structural and rural transformation. Source: Own elaboration based on the Food System dashboard country classification.

conditions of economic and agrarian development. We therefore plotted for the countries included in the FSI database the rate of non-agricultural activities in GDP (ST indicator) against the rural transformation measure (Fig. 4a) and the agricultural value added per worker (RT indicator) against the Food System index (Fig. 4b). The transformation in food systems is clearly enforced by changes in the economic structure. Changes in food systems are thus especially driven by urban food demand and non-agricultural expenditures.

Figure 5 outlines that structural transformation plays a major role during the initial stage of food system transformation, but after a certain threshold food systems become more responsive to processes of change within the agrarian sector. All countries reporting a high FSI are also highly transformed structurally, i.e. more than $80 \%$ of their GDP comes from non-agricultural sectors. At the same time, around $65 \%$ of highly structurally transformed countries (i.e. 49 out of 76), have medium or low FSI - indicating that structural transformation is a necessary but not a sufficient condition to foster a highly performing food system as captured by our multifaceted index. Finally, out of the 28 countries in the low FSI group, 22 report a low rural transformation (i.e. value added per worker in agriculture is below the sample median of US\$1553) and low structural transformation levels. Rural transformation in and of itself (without structural transformation) is not enough either:

Different combinations of structural economic transformation and agrarian change give way to a variety of opportunities and constraints for processes of food systems transformation. This is related to adjustment in the (urban/rural) population structure, changes in public investments for collective services (education, health, roads, security) and implications for income and wealth distribution.

\section{Relevance and outlook}

Most earlier analyses of food system transformation processes is usually based on detailed insight in individual drivers and major outcomes, whereas far less attention is given to mediating processes that reflect structural changes in food production, food markets and trade, food consumption practices, and food policies and the business environment. Instead of disaggregating the common dimensions of food security (i.e. availability, access, affordability, use and stability), we focussed on a set key indicators that critically influence in food systems performance and change. We therefore developed a comprehensive framework that illustrates the structure and dynamics of food system transformation processes at national and regional level, where major policy decisions are taken.

We relied on the structure-conduct-performance approach to classify food systems factors related to structural drivers (exogenous inputs), food systems components (endogenous outputs) and nutritional and environmental outcomes (final impact). It should be acknowledged that better synergies between food system components create opportunities for reducing trade-offs between food system outcomes. This permits us to appreciate the multi-layered context of food systems as well as the multi-dimensional character of food systems change. This can be considered as an important step forward compared to the many partial indicators that have been used until now.

The clear advantage of the FSI approach is the recognition of interactions between key food systems components that can either constrain or reinforce desired food system outcomes. These interactions can only be captured in a multivariate framework. Further analysis of the relationships between food production, trade, consumption and governance could also be based on more advanced systems modelling (Aslihan et al., 2021).

We could take advantage of recent progress in systematic big data collection efforts by several international agencies such as FAO, IFAD and IFPRI, and benefit from the efforts by colleagues from GAIN and Johns Hopkins for putting together the food systems dashboard. Taking stock of these data bases, the food systems index offers a promising framework for comparative appraisal of national food systems and for the analysis of the dynamics of food system transformation processes. 


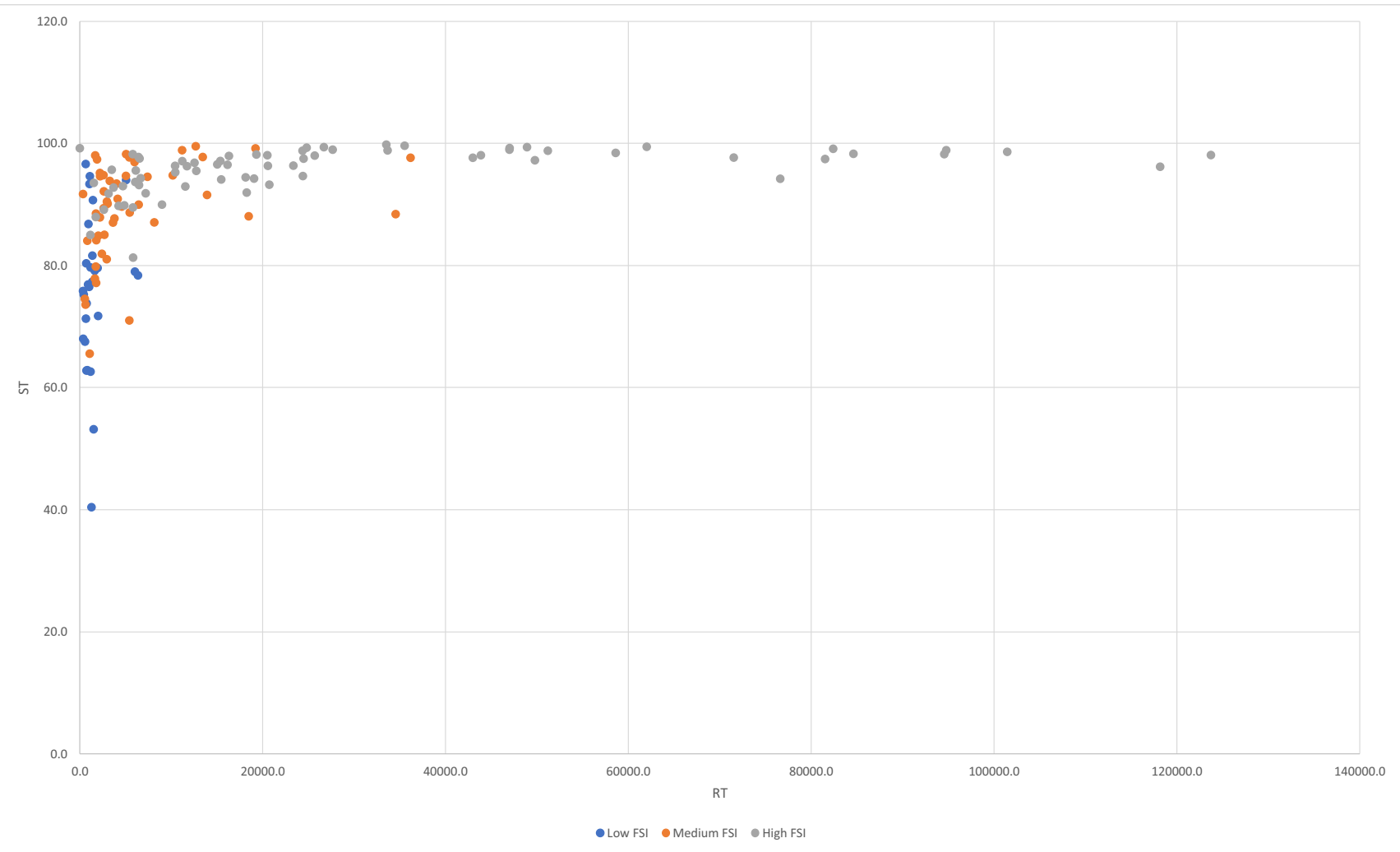

Fig. 5 Relationship between socio-economic change and Food Systems transformation

The practical relevance of the FSI approach is based on its usefulness for policy analysis. Instead of partial appraisal of the effects of incentives on each of the food system components, the FSI framework asks for attention for policy coherence: the advantages of deliberate coordinated action by public, private and civic stakeholders for creating synergies across socio-economic and environmental areas (Frank et al., 2010). We should be careful, however, to use the FSI to assess the effectiveness of specific instruments in the context of individual countries. Since we focus especially on the coherence and consistency between food system dimensions, this goes at the expense of the robustness of individual parameters.

The FSI approach needs to address several major challenges before it can be used for a more detailed analysis of food system dynamics at country level. First, it is recommended to refine the selected indicators with more precise proxies, especially for food trade and food governance. Second, it is necessary to increase the number of food systems outcomes to capture also changes in inclusiveness and equity. Third, we need to be better also to identify most important leverage points for improving food system performance in order to support policy targeted and coherence. These future challenges can only be addressed by working together in research teams composed of different disciplines.

We should acknowledge, however, that the FSI framework still faces some important limitations. First, the FSI can only be identified at country level, whereas large variations in food systems may occur within countries. This co-existence of different food systems within national borders needs to be captured better. Second, some of the FSI indicators are only collected with irregular time intervals, and the reliability of some other reported data can sometimes be poor. This complicates the regular update of the FSI as a tool for registering progress in food system transformation. Third, the drivers for FSI change might be difficult to disentangle, since different aspects of food markets, food production and consumption and food policies interfere. It is therefore important to consider the FSI as a starting point for subsequent in-depth analysis of the internal food system configuration. We sincerely hope that the FSI can fulfil this function. 


\section{Appendix}

Table 4 Food System Dashboard Country Typology: FS index scores, Structural transformation and rural transformation measures

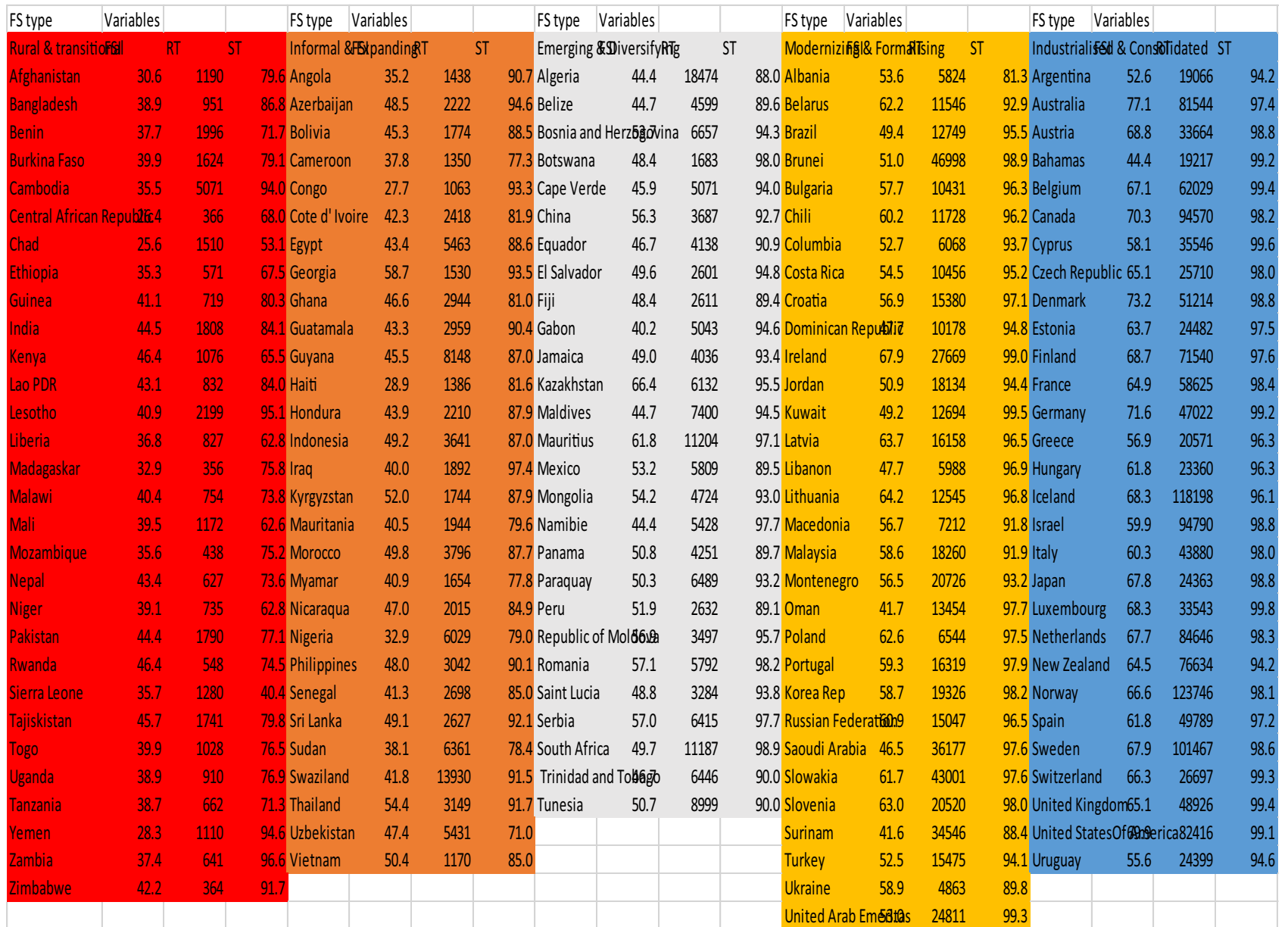

Note: FSI = food system index $(0-100) ;$ ST $=$ Structural Transformation measure, value added non-agricultural activities as \% GDP; RT = Rural Transformation measure, value added per agricultural worker in US\$.

\section{Declarations}

Conflict of interest The authors declare that they have no conflict of interest.

Open Access This article is licensed under a Creative Commons Attribution 4.0 International License, which permits use, sharing, adaptation, distribution and reproduction in any medium or format, as long as you give appropriate credit to the original author(s) and the source, provide a link to the Creative Commons licence, and indicate if changes were made. The images or other third party material in this article are included in the article's Creative Commons licence, unless indicated otherwise in a credit line to the material. If material is not included in the article's Creative Commons licence and your intended use is not permitted by statutory regulation or exceeds the permitted use, you will need to obtain permission directly from the copyright holder. To view a copy of this licence, visit http://creativecommons.org/licenses/by/4.0/.

\section{References}

Allee, A., Lynd, L. R., \& Vaze, V. (2021). Cross-national analysis of food security drivers: Comparing results based on the food insecurity experience scale and global food security index. Food Security. https://doi.org/10.1007/s12571-021-01156-w.

Aslihan, A., Cavatassi, R., \& Hussain, M. (2021). Structural and rural transformation and food systems: A quantitative synthesis for LMICs. IFAD RDR Backgrounds paper.

Béné, C., Prager, S. D., Achicanoy, H. A. E., Toro, P. A., Lamotte, L., Bonilla, C., \& Mapes, B. R. (2019). Global map and indicators of food system sustainability. Sci Data, 6, 279. https://doi.org/10.1038/ s41597-019-0301-5.

Brouwer, I. D., McDermott, J., \& Ruben, R. (2020). Food systems everywhere: Improving relevance in practice. Global Food Security, 26, 100398. https://doi.org/10.1016/j.gfs.2020.100398. 
Christiaensen, L., \& Todo, Y. (2014). Poverty reduction during the ruralurban transformation - The role of the missing middle. World Development, 63, 43-58.

Chen, C., Noble, I., Hellmann, J., Coffee, J., Murillo, M., \& Chawla, N. (2015). University of Notre Dame Global Adaptation Index Country Index Technical Report https://gain.nd.edu/assets/254377/nd_gain_ technical_document_2015.pdf

Cicera, X., \& Masset, E. (2010). Income distribution trends and future food demand. Philosophical transactions of the Royal Society of London. Series B, Biological sciences, 365(1554), 2821-2834. https://doi.org/10.1098/rstb.2010.0164.

CFS (Committee on Food Security) (2014). Global strategic framework for food security and nutrition (GSF). http://www.fao.org/fileadmin/ templates/cfs/Docs1314/GSF/GSF_Version_3_EN.pdf.

Delaney, A., Evans, T., McGreevy, J., Blekking, J., Schlachter, T., Korhonen-Kurki, K., Tamás, P. A., Crane, T. A., Eakin, H., Förch, W., Jones, L., Nelson, D. R., Oberlack, C., Purdon, M., \& Rist, S. (2018). Governance of food systems across scales in times of socialecological change: A review of indicators. Food Security, 10, 287310. https://doi.org/10.1007/s12571-018-0770-y.

D’Odorico, P., Carr, J. A., Davis, K. F., Dell'Angelo, J. L., \& Seekell, D. A. (2019). Food inequality, injustice, and rights. BioScience, 69(3), 180-190. https://doi.org/10.1093/biosci/biz002.

Downs, S. M., Ahmed, S., Fanzo, J., \& Herforth, A. (2020). Food environment typology: Advancing an expanded definition, framework, and methodological approach for improved characterization of wild, cultivated, and built food environments toward sustainable diets. Foods, 9 , 532.

Fanzo, J., Haddad, L., McLaren, R., Marshall, Q., Davis, C., et al. (2020). The food systems dashboard is a new tool to inform better food policy. Nature Food, 5(13), 1-4.

Frank, B., King, M., \& Matthews, A. (2010). Policy coherence for development: Five challenges. Irish Studies in International Affairs, 21, 207-223 http://www.jstor.org/stable/41413183.

GLOPAN. (2016). Food systems and diets: Facing the challenges of the 21st century. Global Panel on Agriculture and Food Systems for Nutrition.

Harris, J., Nesbit, N., \& Baker, P. (2020). Introduction. Towards global nutrition equity. 2020 Global nutrition report Bristol. Development Initiatives.

Hirvonen, K., Bai, Y., Headey, D., \& Masters, A. (2019) Cost and affordability of the EAT-Lancet diet in 159 countries. The Lancet, June 17, 2019). https://ssrn.com/abstract=3405576

Hospes, O. \& A. Brons (2016). Food system governance: A systematic literature review. In: A. Kennedy \& J. Liljeblad (Eds.), Food systems governance. Routledge, pp 13-42.

HLPE (2017). Nutrition and food systems. A report by the High Level Panel of Experts on Food Security and Nutrition of the Committee on World Food Security. Rome: CFS.

Kennedy, E., \& Peters, P. (1992). Household food security and child nutrition: The interaction of income and gender of household head. World Development, 20(8), 1077-1085. https://doi.org/10.1016/ 0305-750X(92)90001-C.

Malapit, H., Meinzen-Dick, R., Quisuming, A., \& Zseleczky, L. (2020). Transforming food Systems for Empowerment and Equity. Chapter 4 global food policy report 2020. IFPRI.

Ruben, R., Verhagen, J., \& Plaisier, C. (2019). The challenge of food systems research: What difference does it make? Sustainability (Switzerland), 11(1) [171]. https://doi.org/10.3390/su11010171.

Sassi, M. (2020). Evidence of between- and within-household child nutrition inequality in Malawi: Does the gender of the household head matter? The European Journal of Development Research, 32, 28 50. https://doi.org/10.1057/s41287-019-00220-8.
Timmer, P. (1988). The agricultural transformation. Chapter 7 handbook of development economics. Elsevier, Volume, 1, 275-331. https:// doi.org/10.1016/S1573-4471(88)01011-3.

Vandercasteelen, J., Beyene, S. T., Minten, B., \& Swinnen, J. (2018). Cities and agricultural transformation in Africa: Evidence from Ethiopia. World Development, 105, 383-399.

Zhou, Y., \& Staatz, J. (2016). Projected demand and supply for various foods in West Africa: Implications for investments and food policy. Food Policy, 61, 198-212.

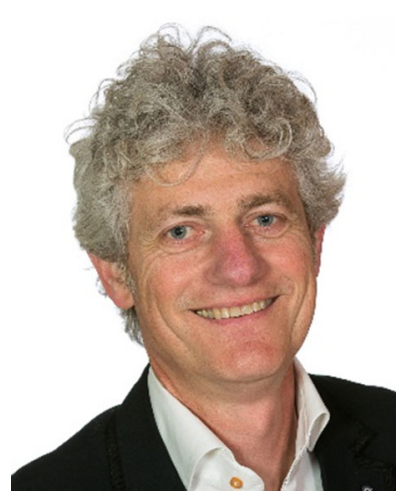

Siemen van Berkum is a senior researcher at Wageningen Economic Research, with extensive research experience in agricultural and trade policy analysis, food supply chain studies and food system analysis. He has contributed a.o. to EU-financed research projects A G R I C I S T R A D E a n d FOODSECURE, and has been involved in research commissioned by EU DG AGRI, SCAR, OECD, IFAD, FAO and World Bank, next to research funded by foreign government and non-governmental bodies. Currently Siemen co-coordinates an IFAD commissioned assignment 'Food systems Transformations', the results of which will feed into IFAD's Rural Development Report 2021. Siemen drafted a number of reports analysing the implications and operationalisation of food systems thinking in Dutch aid and investment programmes.

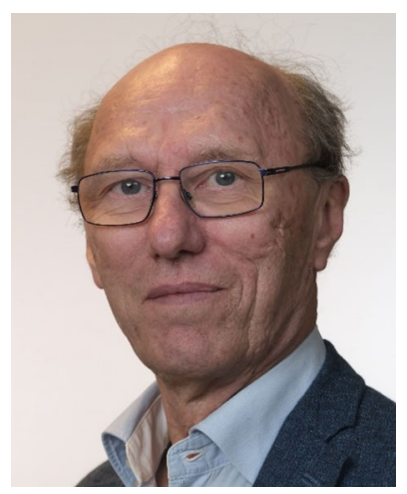

Ruerd Ruben holds the special chair of Impact Analysis for Food Systems at Wageningen University and Research. He serves at the planning and management committee of the IFPRI-led CGIAR research program "Agriculture for Nutrition and Health" (A4NH). He is member of the supervisory board of the Netherlands Food Partnership (NFP) and board member of the FoodFirst coalition. He was involved in policy research on the dynamics of food systems, opportunities for smallholder involvement in tropical agri-food value chains, the effectiveness of incentives healthier diets, and the impact of standards and certification. He published more than 100 articles in peer-reviewed journal and co-edited 12 books with academic publishers. He served earlier as director of the independent Policy and Operations Evaluation (IOB) department at the Netherlands Ministry of Foreign Affairs and as professor in Development Effectiveness and Director of the Centre for International Development Issues (CIDIN) at Radboud University Nijmegen. 